\title{
Pesquisa e prática discursiva sobre currículo na comunidade acadêmico- científica: territórios e conexões
}

\author{
Researches and discursive practices about curriculum in the scientific- \\ academic community: territories and connections
}

\section{Investigaciones y prácticas discursivas sobre currículo en la comunidad académico-científica: territorios y conexiones}

\author{
Sandra Kretli da Silva ${ }^{2}$ \\ Priscila dos Santos Moreira ${ }^{3}$ \\ Nathan Moretto Guzzo Fernandes ${ }^{4}$
}

\begin{abstract}
Resumo: O artigo é decorrente de uma pesquisa maior cujo objetivo é cartografar práticas discursivas sobre currículo da comunidade acadêmico-científica vinculadas às associações do campo e propagadas no periódico internacional Transnacional Curriculum Inquiry (TCI) e nos dossiês organizados pela Associação Brasileira de Currículo (ABdC) publicados nas revistas nacionais Currículo sem Fronteiras, e-Curriculum e Teias. Problematiza as vinculações institucionais dos autores que publicaram na TCI e nos dossiês da $\mathrm{ABdC}$, a partir do diálogo com Gilles Deleuze, Félix Guattari e Michel Foucault entre agenciamentos coletivos de enunciação que desenham territórios. Evidencia o pensamento-diferença e propaga a ampliação dos espaços de abertura para publicação das pesquisas produzidas por autores vinculados a diferentes instituições e da participação de outras associações e entidades internacionais, com vistas à expansão das conexões nos periódicos do campo curricular.
\end{abstract}

Palavras-chave: Currículos. Pesquisas. Territórios.

\begin{abstract}
The article results from a greater study, which purpose is mapping discursive practices about curriculum regarding the academic-scientific community linked to associations' field and spread in the international journal named Transnational Curriculum Inquiry (TCI) and in the portfolios organized by the Curriculum Brazilian Association (CBA) published in the national magazines named Currículo sem Fronteiras, e-Curriculum and Teias. The study discusses the institutional links of the authors that published in the TCI magazine and the CBA portfolios, based on the dialogues with com Gilles Deleuze, Félix Guattari and Michel Foucault among the utterance collective agencying that designs territories. The work highlights the thinkingdifference and propagates the expansion of the opening spaces used to publish the researches produced by authors linked to different institutions and the participation of other associations and international entities, in order to expand the connections of the curricular journals field.
\end{abstract}

Keywords: Curriculum. Researches. Territories.

Resumen: El artículo es resultado de una investigación mayor cuyo objetivo es cartografar prácticas discursivas sobre currículo de la comunidad académico-científica vinculadas a las asociaciones del campo y propagadas en el periódico internacional Transnacional Curriculum Inquiry (TCI) y en los dosiers organizados por la Asociación Brasileña de Currículo (ABdC) publicados en las revistas nacionales Currículo sem Fronteiras, y Curriculum e Teias. Problematiza los vínculos institucionales de los autores que publicaron en la TCI y en los dosiers de la ABdC, a partir del diálogo con Gilles Deleuze, Félix Guattari y Michel Foucault entre agenciamentos colectivos de enunciación que diseñan territórios. Evidencia el pensamiento-diferencia y propaga la ampliación de los espacios de abertura para publicación de investigaciones producidas por autores vinculados a diferentes instituciones y de la participación de otras asociaciones y entidades internacionales, con vistas a la

\footnotetext{
${ }^{1}$ Submetido em: 04 fev. 2019 - Aceito em: 16 jun. 2019 - Publicado em: 22 nov. 2019

${ }^{2}$ Universidade Federal do Espírito Santo (UFES) - E-mail: sandra.kretli@ hotmail.com

${ }^{3}$ Universidade Federal do Espírito Santo (UFES) - E-mail: moreira-priscila@ hotmail.com

${ }^{4}$ Universidade Federal do Espírito Santo (UFES) - E-mail: nathanmoretto1 @ hotmail.com
} 


\section{Movimentos de (des)(re)territorialização entre linhas desejantes: composições micromacropolíticas no campo curricular}

Desejar é construir um agenciamento.
$[\ldots]$ Só há desejo em conjunto,
em uma articulação, em uma conexão (DELEUZE).

Esta pesquisa compõe um projeto mais amplo, nomeado "Práticas discursivas sobre currículo da comunidade acadêmico-científica vinculadas às associações do campo e propagadas em periódicos nacionais e internacional" - cujo objetivo é cartografar relações entre as práticas discursivas sobre currículo, a partir dos enunciados discursivos dos autores expressos no periódico internacional Transnacional Curriculum Inquiry (TCI) e nos dossiês organizados pela Associação Brasileira de Currículo ( $\mathrm{ABdC}$ ) publicados nos periódicos nacionais Currículo sem Fronteiras, e-Curriculum e Teias.

A TCI é uma revista que expressa alguns dos movimentos de transnacionalização do campo curricular propostos pela International Association for the Advancement of Curriculum Studies (IAACS). Desse modo, optamos por realizar um acompanhamento cartográfico discursivo - atravessado por diversas concepções epistemológicas - no período de 2010-2016, com vistas à continuidade da pesquisa publicada por Carvalho (2013) que abarcou a análise desse periódico de 2004 a 2009.

A ABdC é uma associação brasileira recente sem fins lucrativos, criada em oito de junho de 2011, em uma assembleia realizada durante o VI Seminário Internacional "As redes educativas e as tecnologias: práticas/teorias sociais na contemporaneidade", no Rio de Janeiro. $\mathrm{O}$ objetivo da $\mathrm{ABdC}$ é agregar profissionais, pesquisadores e estudantes que realizam atividades de pesquisa e/ou docência e/ou extensão no campo do currículo. Desse modo, nesta cartografia, propusemo-nos analisar os artigos que compuseram os dossiês da associação veiculados em três periódicos - durante o primeiro quinquênio dessas publicações.

Em um dos encontros entre os membros da $\mathrm{ABdC}$, foi proposta a organização de dossiês temáticos a serem veiculados nos periódicos de boa circulação no campo curricular, a fim de divulgar e difundir as pesquisas com destaque na área. $\mathrm{Na}$ ocasião, três periódicos se disponibilizaram a publicar os dossiês organizados pela $\mathrm{ABdC}$ : Currículo sem Fronteiras, eCurriculum e Teias. Assim, linhas de vida possíveis se entrelaçaram por meio dos relatos de pesquisas apresentados no campo do currículo, expandindo encontros e novas conexões.

A revista Currículo sem Fronteiras é classificada como A2 na avaliação da Coordenação de Aperfeiçoamento de Pessoal de Nível Superior (CAPES) com publicação quadrimestral desde 2012 (ocasião em que um desses volumes passou a ser organizado pela $\mathrm{ABdC}$ ). Não possui vínculo com nenhuma Universidade específica. Tem editores membros de 
três instituições diferentes, a saber: University of Massachusetts - Dartmouth, Universidade Federal do Rio Grande do Sul e Universidade Federal de Pelotas.

A e-Curriculum é do Programa de Pós-Graduação em Educação: Currículo, da Pontifícia Universidade Católica de São Paulo (PUC-SP). A publicação é quadrimestral (e um desses volumes compete à $\mathrm{ABdC}$ ), e também recebeu qualificação $\mathrm{A} 2$ na análise da Capes. $\mathrm{A}$ revista se propõe discutir os campos das Políticas Públicas de Educação, Formação de Educadores, Tecnologias da Educação, Conhecimento e Cultura, Avaliação e Interdisciplinaridade.

O periódico Teias é do Programa de Pós-Graduação em Educação da Universidade do Estado do Rio de Janeiro (UERJ). Também foi muito bem avaliado pela CAPES (Qualis B1). Sua periodicidade é trimestral (um desses volumes é organizado pela $\mathrm{ABdC}$ ). Esse periódico objetiva incentivar a pesquisa e o debate da área da Educação, centrados nas suas relações com a sociedade.

Especificamente, o objetivo deste artigo consiste na problematização das vinculações institucionais dos autores que publicaram na TCI e nos dossiês da ABdC, a partir do diálogo com Gilles Deleuze, Félix Guattari e Michel Foucault, para a análise dos complexos fios tecidos entre relações de poder e agenciamentos coletivos de enunciação que desenham esses territórios. Com Deleuze e Parnet (1998, p. 84), afirmamos que esse agenciamento "[...] é uma multiplicidade que comporta muitos termos heterogêneos e que estabelece ligações, relações entre eles, por meio das idades, sexos, reinos - de naturezas diferentes". Com Guattari (2012, p. 47), é "[...] um agenciamento no campo de possíveis, de virtuais tanto quanto de elementos constituídos sem noção de relação genética ou de espécie”.

Nesse sentido, compreendemos que há relações entre agenciamentos e territórios, pois o "[...] território cria o agenciamento e o agenciamento ultrapassa o simples "comportamento"” (DELEUZE; GUATTARI, 1997, p. 128). O território, como campo de poder, decorre de uma produção que envolve as múltiplas relações estabelecidas nas redes de poderes, de afetos e de afecções. Por isso, a territorialidade deve ser aqui entendida como resultante de permanente disputa de poderes relacionais, que se deslizam e ou deslocam em função de movimentos, ações e posições estratégicas de vínculos institucionais dos pesquisadores.

Movimentamos o pensamento com Deleuze (1988), entre as linhas desejantes, entendendo que as subjetividades, as enunciações, os desejos não são simplesmente internos, individuais e nem produzidos de maneira isolada, mas na relação com um conjunto de paisagens, pessoas, encontros e entre os emaranhados de fios das três linhas: dura/molar, flexível/molecular e de fuga (DELEUZE; PARNET, 1998) que coexistem nas composições micromacropolíticas (DELEUZE; GUATTARI, 2012) do campo curricular.

Podemos associar o emaranhado dessas linhas desejantes às composições do território, pois, segundo Deleuze e Guattari (2012), a desterritorialização é o movimento pelo qual se abandona o território. É a operação da linha de fuga. Dessa maneira, a territorialidade é apenas um dos aspectos do agenciamento e o outro está relacionado com as linhas de desterritorialização que o atravessam e o arrastam. 
Em consonância com Deleuze e Parnet (1998), podemos afirmar que não há agenciamento sem território, territorialidade e reterritorialização, mas tampouco há agenciamento sem ponta de desterritorialização, sem linha de fuga, que o carrega para novas criações ou para a morte. Ou seja, a linha de fuga permite o desmanche do que está formatado, criando outros possíveis imprevisíveis, com novos agenciamentos em vibrações e intensidades que escapam às dogmatizações e linhas enrijecidas no território-currículo.

Nesse mesmo direcionamento, os enunciados são produzidos entre agenciamentos e movimentos de (des)(re)territorializações. Segundo Deleuze e Guattari (2012), o enunciado é a palavra de ordem. As palavras de ordem não remetem somente a comandos, mas a todos os atos que estão ligados aos enunciados por uma "obrigação social". Considerando essa premissa, não existe enunciação individual, nem mesmo sujeito de enunciação. A enunciação remete, por si mesma, aos agenciamentos coletivos.

É sempre um agenciamento que produz os enunciados. "O enunciado é produzido por um agenciamento, sempre coletivo, que põe em jogo, em nós e fora de nós, populações, multiplicidades, territórios, devires, afetos, acontecimentos" (DELEUZE; PARNET, 1998, p. 65). Nesse sentido,

[...] um agenciamento é, a um só tempo, agenciamento maquínico de efetuação e agenciamento coletivo de enunciação. Na enunciação, na produção de enunciados, não há sujeito, mas sempre agentes coletivos. Não há objetos nos enunciados, há estados maquínicos (DELEUZE; PARNET, 1998, p. 85).

A partir dessa fundamentação, nesta pesquisa, ainda que as vinculações institucionais dos autores das pesquisas remetam a lugares específicos, trouxemos o conceito de território acima não para identificar espaços geográficos, enquadrá-los ou fechá-los em identidades/rostos, mas para pensarmos o campo curricular entre essas complexas relações de poder e nas possibilidades de transitoriedade das forçasformas, pois, como afirma Foucault (2007, p. 414): o "[...] território é uma questão geográfica, mas, antes de tudo, uma noção jurídico-política", ou seja, compõe-se de relações de poder.

Consideramos a premissa de que as subjetividades não são produtos desses espaços - e nem se expressam como posse desses autores com seus respectivos vínculos institucionais entretanto, elas são produzidas entre agenciamentos e subjetividades coletivas na teia de movimentos (des)(re)territorializantes cujas forçasformas fazem reverberar alguns enunciados - produzidos nesses espaços - que são selecionados para publicação na TCI e nos dossiês da $\mathrm{ABdC}$ em constituição de possíveis regimes de verdade.

Conforme Foucault (2007), os discursos de verdade são produzidos a partir de um jogo de regras, mecanismos de poder aos quais nossas práticas sociais e culturais pertencem. Assim, cada campo do saber vai se constituindo por regimes de verdade (tipos de discurso que acolhe e faz funcionar como verdadeiros; mecanismos e instâncias que colaboram para enfatizar os enunciados que são legitimados).

Em composição com essas problematizações e com Foucault (2013), afirmamos que o discurso é um conjunto de pensamentos produzidos nas relações de poder entre indivíduos que defendem e legitimam as ideias dominantes de uma dada época. Nesse sentido, as práticas 
discursivas são práticas de poder que não são simplesmente modos de fabricação de discursos, mas que vão se constituindo por meio das instituições, dos esquemas de comportamentos e das formas pedagógicas que as impõem e as mantêm.

Nesse sentido, problematizamos: quais países e universidades estão sendo evidenciados quanto às vinculações institucionais dos autores e que ausências têm sido produzidas pela transnacionalização objetivada pela TCI? No caso dos dossiês da $\mathrm{ABdC}$, de quais regiões do país falam os autores? Quais são as associações e composições realizadas entre as diversas instituições? Os pesquisadores que atuam nas escolas da Educação Básica compõem esses enunciados? As enunciações abarcam uma multiplicidade de vozes brasileiras e estrangeiras? Quais são os estados brasileiros recorrentemente visibilizados nessas publicações institucionais e quais estão ausentes nessas demarcações autorais desenhadas entre relações de podersaber? Por que esses enunciados sobressaem? Que outros enunciados estão sendo silenciados no campo do currículo?

\section{Associação Brasileira de Currículo (ABdC): múltiplas vozes no campo curricular nacional?}

Considerando os dossiês da $\mathrm{ABdC}$, enfatizamos que, na primeira revista analisada, Currículo sem Fronteiras, no que concerne à autoria dos editoriais, todos os pesquisadores no período analisado - possuíam vínculo com instituições situadas na Região Sudeste do Brasil. Em cada ano, o dossiê foi organizado por dois professores que atuavam nessa região, a saber: PUC-SP e Universidade Estadual de Campinas (Unicamp) em 2012; UERJ e Universidade Federal do Espírito Santo (UFES) em 2013; Unicamp e PUC-SP em 2014; UERJ e UERJ em 2015; e Universidade Federal de Minas Gerais (UFMG) e UFES em 2016. Evidenciamos que todos os dez organizadores eram vinculados a universidades localizadas na Região Sudeste.

Já na Revista e-Curriculum, a organização dos editoriais ficou a cargo de dois pesquisadores, por volume, com vínculos institucionais nas Regiões Sudeste e Sul: UERJ e UERJ em 2012; Universidade Federal do Rio Grande do Sul (UFRGS) e Universidade Federal de Pelotas (UFPel) em 2013; UERJ e Universidade Federal do Estado do Rio de Janeiro (Unirio) em 2014; UERJ e PUC-SP em 2015; e PUC-SP e UERJ em 2016. Entretanto, ressaltamos que essa Revista é do Programa de Pós-Graduação da PUC-SP e, desse modo, excetuando-se a participação de pesquisadores com vínculos nessa instituição, apenas o Rio de Janeiro foi representado dentro da Região Sudeste e somente o Rio Grande do Sul na Região Sul.

Na Revista Teias, cada dossiê também foi organizado por dois pesquisadores: Unicamp e PUC-SP em 2013; UFPel e UFPel em 2014; Universidade Federal da Bahia (UFBA) e Universidade Federal do Rio de Janeiro (UFRJ) em 2015; Universidade Federal de Santa Catarina (UFSC) e UFRJ em 2016. Desse modo, ainda que a Região Sudeste, por meio dos estados do Rio de Janeiro e São Paulo, se destaque no que tange aos vínculos autorais, a Região Sul também aparece e, uma vez, a Região Nordeste. 
Podemos evidenciar as vinculações institucionais dos organizadores dos dossiês da $\mathrm{ABdC}$ como um todo expresso nos três periódicos, da seguinte forma (Gráfico 1):

Gráfico 1. ABdC - Vínculos institucionais dos organizadores

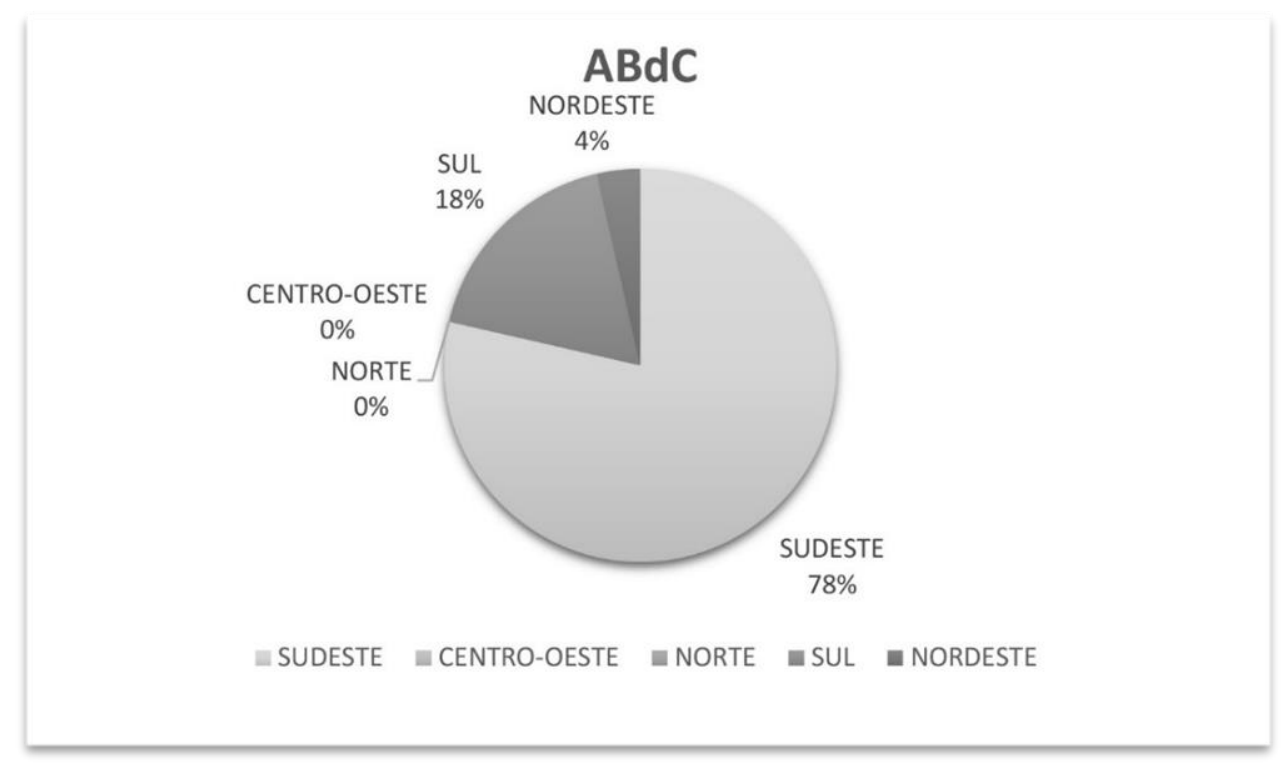

Fonte: Elaborado pelos autores (2018) com base nos dados do dossiê da ABdC (2012-2016).

Em relação aos artigos publicados nesses dossiês, identificamos que, na Revista Currículo sem Fronteiras, dos 62 estudos apresentados e produzidos por 118 autores, no que tange aos vínculos nacionais dos autores, a UERJ se destaca com nove artigos (15\%), dois desses escritos em coautoria com professores da Universidade Federal do Mato Grosso (UFMT) 3\% e com a UFES. A UFES aparece em seguida com oito artigos (13\%), quatro desses em coautoria com a Universidade de Lisboa, a Universidade Vila Velha (UVV), o Instituto Federal do Espírito Santo (IFES) e a UERJ.

O terceiro estado que apareceu de modo mais evidente foi São Paulo, no qual a Unicamp e a PUC-SP são evidenciadas com sete artigos (11\%) cada uma. Desse modo, os estados que se destacaram nesse escopo integram a Região Sudeste. Cabe salientar que, com exceção de uma, todas as demais instituições representadas com dois artigos ou mais estão situadas nas Regiões Sudeste e Sul do país. Os lugares de onde as práticas discursivas sobre currículo são legitimadas, nos dossiês publicados nessa revista, apontam 41 instituições diferentes das quais, aproximadamente $85 \%$, são universidades; 5\% são Institutos Federais de Educação; e 10\% correspondem às redes de ensino estaduais e municipais. Dessas 41 instituições, 32 são nacionais $(78 \%)$.

Das 32 instituições nacionais, 50\% encontram-se na Região Sudeste, 25\% na Região Sul, 16\% na Região Nordeste, 6\% na Região Norte e 3\% na Região Centro-Oeste (os 24 artigos vinculados às instituições localizadas nas Regiões Sul e Sudeste correspondem a $75 \%$ do total de instituições nacionais, demonstrando uma diferença considerável comparada com o restante do país e uma correspondência com as regiões evidenciadas nos vínculos dos pesquisadores 
que integraram os editoriais). Dessas instituições, 24 (75\%) são públicas (15 federais, 7 estaduais e 2 municipais) e oito (25\%) são privadas. No que tange às regiões em que estão localizadas as instituições, as quais os autores e coautores estão vinculados, temos o Gráfico 2:

Gráfico 2. Revista Currículo sem Fronteiras: vínculos institucionais dos autores

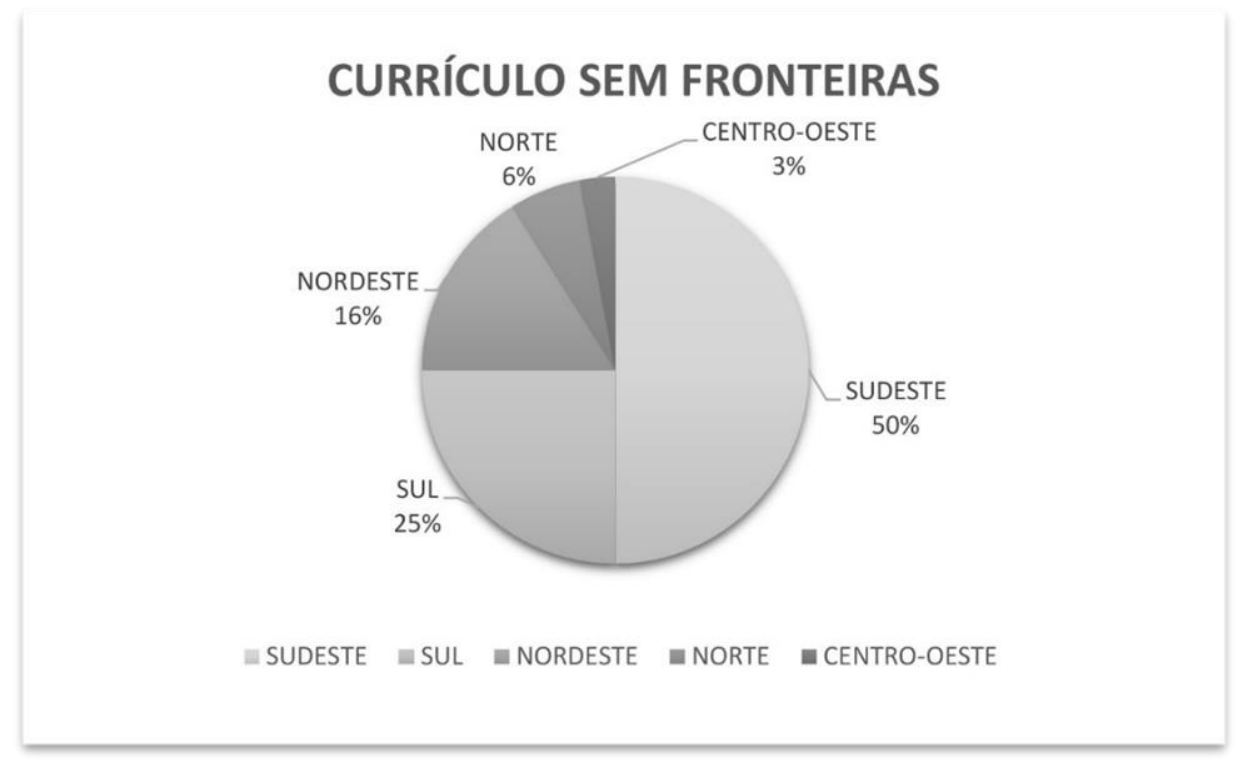

Fonte: Elaborado pelos autores (2018) com base nos dados do dossiê da ABdC (2012-2016).

Já na análise da e-Curriculum, enfatizamos que, dos 50 artigos produzidos, 42 foram escritos por pesquisadores que possuem vínculos com instituições nacionais. Desses, 66\% estão localizados na Região Sudeste (na qual se destaca fortemente o Rio de Janeiro por meio da UERJ). Os estados de Minas Gerais e Espírito Santo comparecem com apenas um artigo cada um. Cabe salientar que, apesar de a e-Curriculum pertencer a um programa de pósgraduação situado no Estado de São Paulo, no que concerne aos dossiês da ABdC, a participação desse estado não foi evidenciada.

Os dados apontaram que $18 \%$ das pesquisas foram publicadas por autores que atuam em instituições localizadas na Região Sul. O Rio Grande do Sul é o estado de maior destaque dentro dessa Região. É representado pelas seguintes instituições: UFPel, UFRGS e também a partir de artigos escritos por mais de um autor, com vínculos em diferentes instituições, entretanto localizadas no mesmo estado: UFPel e UFRGS; UFPel e Universidade Federal de Santa Maria (UFSM); Universidade de Santa Cruz do Sul (Unisc) e UFRGS.

Aproximadamente, $16 \%$ dos autores estão vinculados a universidades que integram a Região Nordeste. Há que se complementar que, em dois artigos, as autoras possuem vínculo de trabalho nessa região, contudo a pesquisa de doutoramento também foi orientada no Programa de Pós-Graduação da UERJ. É imprescindível comentar ainda que, em nenhum dos artigos publicados, o(s) autor(es) possuíam vínculos com quaisquer instituições localizadas em algum dos estados das Regiões Centro-Oeste e Norte. Evidenciamos, nessa revista, que apenas as Instituições de Ensino Superior foram representadas nos artigos como um todo. 
Enfatizamos que a predominância do Rio de Janeiro (RJ) destaca-se no marco de análise desse periódico, pois, dos 50 artigos, quase a metade foi escrita por pesquisadores filiados a instituições situadas nesse estado: 16 desses artigos foram escritos por autores com vínculo institucional com a UERJ, e os demais por autores com vínculo com a Pontifícia Universidade Católica do Rio de Janeiro (PUC-RJ), Unirio e UFRJ. Podemos visualizar, por meio do gráfico abaixo, os estados em que todas as instituições estão localizadas:

Gráfico 3. Revista e-Curriculum: vínculos institucionais dos autores

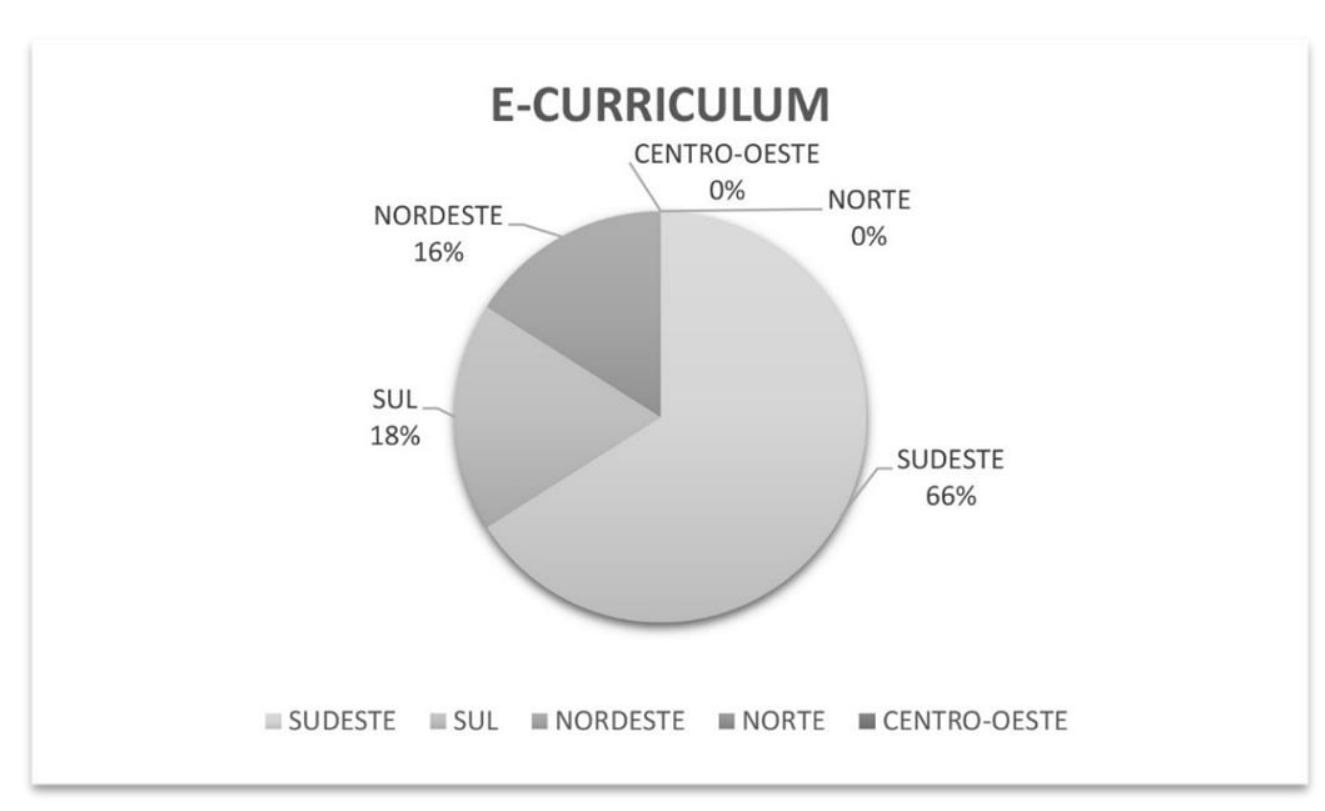

Fonte: Elaborado pelos autores (2018) com base nos dados do dossiê da ABdC (2012-2016).

Na terceira revista (Teias), observamos que, dos 26 artigos - escritos por 40 autores 25 eram de pesquisadores com vínculos nacionais. A Região Sudeste destacou-se no que concerne à localização dessas instituições, mas percebemos uma maior participação de autores cujos vínculos apontam outras regiões do país, se compararmos essa revista com os demais dossiês da Associação.

A Região Sudeste foi representada por São Paulo (oito artigos), Rio de Janeiro (quatro), Minas Gerais (um) e Espírito Santo (um). A Região Nordeste: Bahia (três), Pernambuco (três), Paraíba (um) e Sergipe (um). As demais regiões foram representadas apenas por um estado em cada região: Região Sul: Rio Grande do Sul (três instituições), Região Norte: Pará (duas instituições) e Centro-Oeste: Goiás (duas instituições). Enfatizamos ainda que nos dossiês publicados na Teias, é possível verificar uma maior participação de autores vinculados às escolas públicas estaduais e municipais, se compararmos com as demais revistas da $\mathrm{ABdC}$. Podemos observar essa análise no gráfico adiante: 
Gráfico 4. Revista Teias: vínculos institucionais dos autores

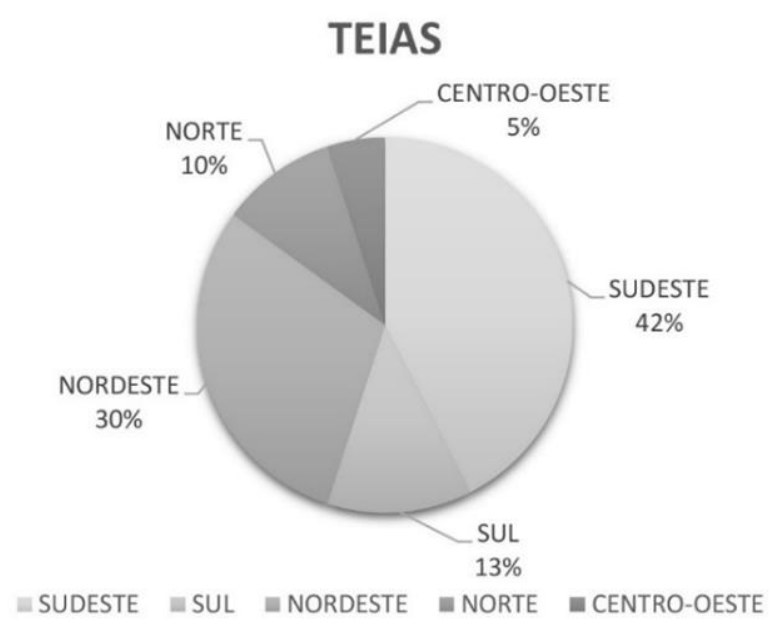

Fonte: Elaborado pelos autores (2018) com base nos dados do dossiê da ABdC (2012-2016).

Diante desse cenário - sem a intenção de responder, entretanto, de movimentar o pensamento - problematizamos: como as relações de formasforças são enredadas de modo que as instituições da Região Sudeste sejam tão evidenciadas nas produções discursivas acolhidas nos dossiês das três revistas? De que modos essas tramas poderiam ser agenciadas visando ao fortalecimento da participação dos professores das redes de ensino estaduais e municipais nos artigos publicados nos dossiês da ABdC? Como ampliar o processo evidenciado em uma das três revistas, de modo que fortaleça a participação de professores das instituições escolares? Que encontros/forças podem favorecer a expansão de instituições que obtiveram pouca expressividade nas publicações desses dossiês? Que teias complexas são emaranhadas para que um estado - especificamente uma instituição - tenha tido maior produtividade e visibilidade em uma dessas três revistas? Como essas composições produzem relações de forças e movimentam/(des)(re)territorializam o campo curricular e as enunciações da $\mathrm{ABdC}$ ?

Considerando o objetivo da $\mathrm{ABdC}$ - que, conforme exposto no site, consiste em agregar profissionais e pesquisadores do campo do currículo - que possíveis (CARVALHO, 2009) podem ser inventados, visando à expansão desses diálogos e à multiplicação dessas vozes para que a Associação se efetive como organização que abarca autorias de diversas Regiões do País? Que outras conexões podem ser produzidas para potencializar os estudos e as práticaspolíticas no campo do currículo? Como podemos compor com as diferenças de enunciados que desmontam e formam novos possíveis no campo curricular? 
Vínculos institucionais dos autores da Transnacional Curriculum Inquiry (TCI) e vínculos institucionais dos autores estrangeiros que publicaram nos dossiês da ABdC: múltiplas vozes no campo curricular internacional?

Durante o período analisado, 2010 a 2016, o periódico editou 14 números, em 2 volumes anuais, totalizando 66 artigos produzidos por 96 autores. Percebemos uma concentração das autorias em alguns países, pois aproximadamente $46 \%$ dos estudos publicados são de autores canadenses, $21 \%$ de autores brasileiros e $11 \%$ de norte-americanos. Ou seja, esses três países juntos somaram quase $80 \%$ da origem dos escritores.

No que tange às instituições em que os pesquisadores atuam, enfatizamos que quase $60 \%$ estão localizadas na América do Norte (46\% no Canadá e 11\% nos Estados Unidos da América (EUA)). A participação do Brasil é de 21\%, 6\% em Portugal e 4\% no México. A dos demais países é percebida do seguinte modo: $2 \%$ em cada um dos países, como: Argentina, Dinamarca, Finlândia e Taiwan; e 1\% nos seguintes países: Turquia; África do Sul; Chipre e China.

Evidenciamos que, além do Brasil (21\%), há participação localizada de autores com vínculos institucionais em outro país situado na América do Sul: Argentina (2\%). Outros continentes foram sub-representados no que concerne aos vínculos institucionais autorais: África: África do Sul (1\%); Ásia: China (1\%) e Taiwan (2\%); Europa: Dinamarca (2\%), Finlândia (2\%), Portugal (6\%) e Turquia (1\%), Chipre (1\%), como demonstra o Gráfico 5:

Gráfico 5. Revista TCI: vínculos institucionais dos autores

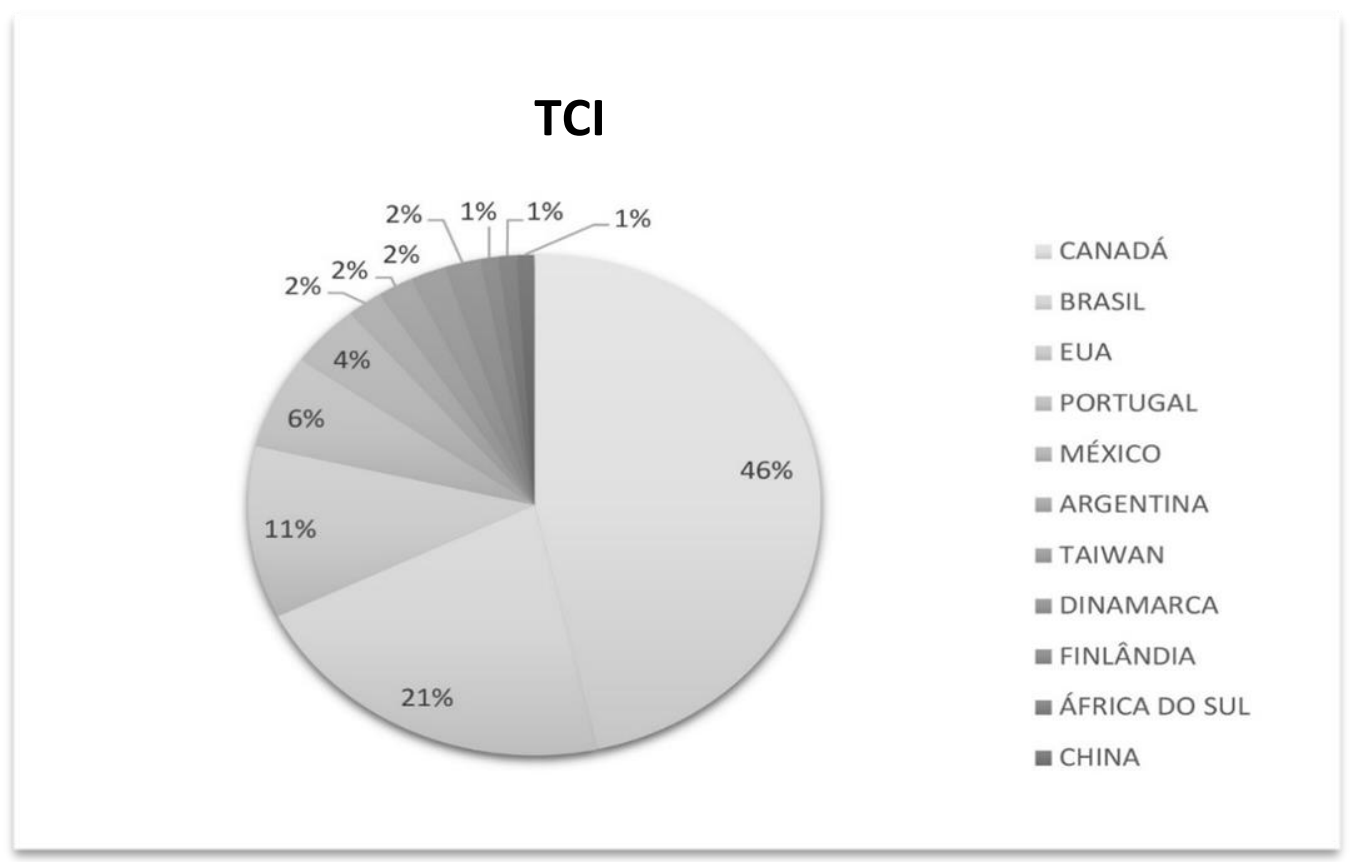

Fonte: Elaborado pelos autores (2018) com base nos dados da TCI (2010-2016). 
A partir da análise das instituições em que os autores atuam, evidenciamos que a maioria dos artigos publicados são de pesquisadores da University of British Columbia e da University of Ottawa, localizadas no Canadá, e da UERJ no Brasil. Desse modo, movimentamos o pensamento no sentido de que, dentro da proposta de transnacionalização, urge escapar das circularidades de sentidos criados nessa produção discursiva que desenha esse território-campo de pesquisa curricular entre relações de poder e agenciamentos coletivos.

Nesse mesmo direcionamento, no que compete aos vínculos internacionais dos autores que publicaram nos dossiês da $\mathrm{ABdC}$, evidenciamos que, na Currículo sem Fronteiras, 9 artigos (22\% dos 62 artigos) foram escritos por autores vinculados a instituições estrangeiras. Argentina e Portugal foram países que se destacaram. Cada um dos escritores era vinculado a três instituições diferentes: Universidad de Buenos Aires, Universidad Nacional de San Martín e Universidad Nacional de La Plata, na Argentina; e, em Portugal, os autores atuavam na Universidade do Minho, Universidade de Lisboa e Universidade do Porto. As demais instituições a que os pesquisadores estavam vinculados eram: Universidad Nacional Autónoma (México), Universidade de Wisconsin-Madison (EUA) e Institute of Education (Inglaterra).

$\mathrm{Na}$ e-Curriculum oito artigos (15\% dos 50 artigos) foram produzidos por autores de outros países. Metade desse índice (quatro) era referente especificamente aos EUA (University of Wisconsin-Madison; Arizona State University; Grand Canyon University; National Louis University; Columbia University); e os demais eram: um da Austrália (University of Melbourne), um de Portugal com três autores (Universidade do Porto), um da Suécia (University of Gävle) e um com dois autores da França (Université de Rouen). Já na revista Teias, somente um dos 26 artigos foi escrito por pesquisador com vínculo institucional internacional, a saber Portugal (Universidade do Minho).

Podemos observar esses vínculos internacionais na produção dos dossiês da $\mathrm{ABdC}$ por meio do Gráfico 6:

Gráfico 6. ABdC: vínculos institucionais internacionais dos autores

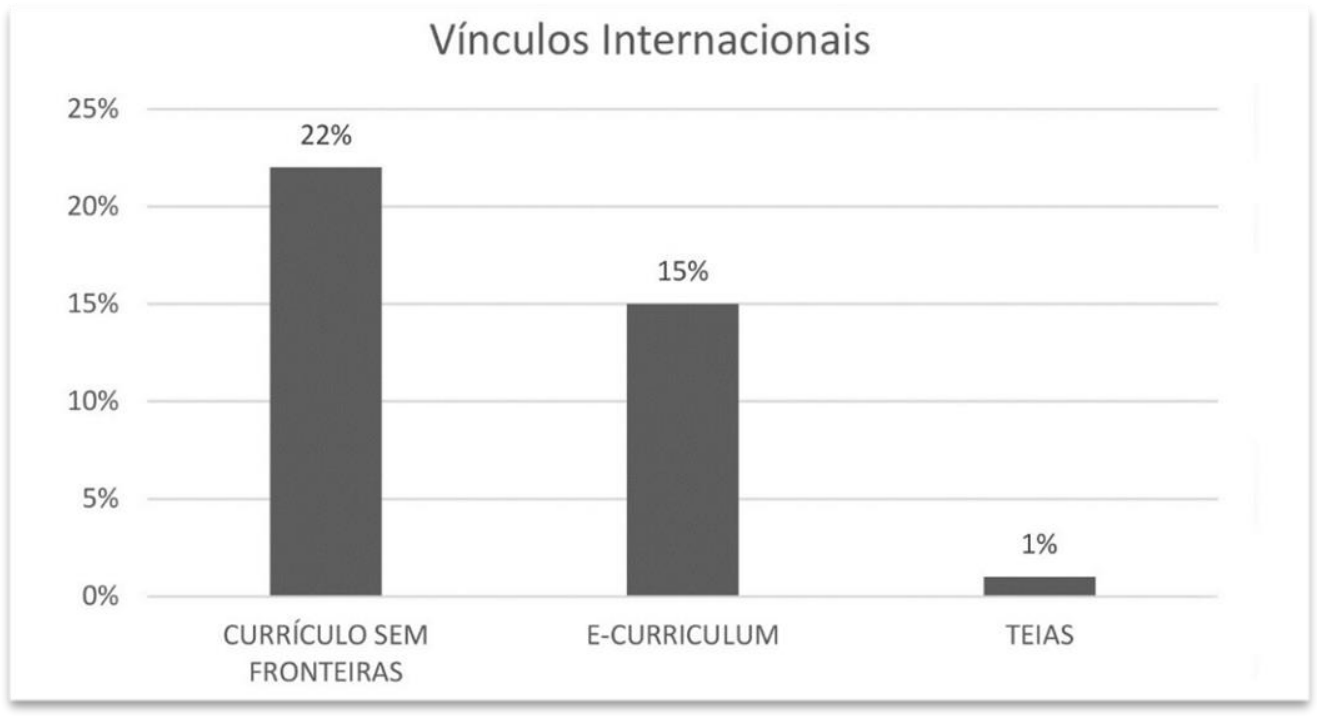

Fonte: Elaborado pelos autores (2018) com base nos dados do dossiê da ABdC (2012-2016). 
Considerando o cenário internacional, evidenciamos que, no que diz respeito ao objetivo de transnacionalização dos estudos sobre o currículo no periódico TCI, urge desterritorializar a atual concentração excessiva das autorias no Canadá, EUA e Brasil nesses enredamentos discursivos, para que essa potência seja ampliada. Baseado na premissa de que a transculturalização e transinternacionalização perpassam as intencionalidades da revista, há que se investir na alteridade e na invenção de modos de produzir conhecimentos, entremeados às múltiplas vozes provenientes de diversos países.

\section{Algumas considerações finais...}

Propagamos a necessidade de ampliar os espaços de abertura para outros sentidos, com vistas à efetiva polifonia. Ainda que os territórios neste artigo não sejam compreendidos como sinônimos de lugares geográficos, problematizamos: de que modos as autorias advindas das diversas instituições e produzidas em diferentes contextos poderiam contribuir nos movimentos de expansão de conexões em um periódico que se propõe transnacional?

Deleuze e Parnet (1998) afirmam que é preciso estudar os movimentos de desterritorialização, os continuums de intensidade e as conjugações de fluxos que os campos sociais concretos formam. Assim, com os autores, enfatizamos que, do mesmo modo como é composto um agenciamento coletivo, múltiplas pontas de des(re)territorializações atravessam, cortam e escoam compondo uma paisagem provisória na produção do conhecimento curricular. Com essas possibilidades, propomos aberturas a outras produções no cenário internacional especialmente no TCI (que se propõe transnacional) e na $\mathrm{ABdC}$ nos possíveis diálogos dessas com as associações internacionais de currículo por meio dos dossiês da Associação Brasileira no campo curricular.

Nesse direcionamento, afirmamos a necessidade de inventar práticas discursivas e agenciamentos coletivos de enunciação e isso implica produzir políticas que se tecem entre multiplicidades de linhas, regimes, (des)caminhos, fugas. Com essa premissa, problematizamos: que possibilidades de vida e novas composições curriculares podem ser inventadas a partir dos agenciamentos coletivos engendrados por meio das enunciações expressas nas publicações da $\mathrm{ABdC}$ e do TCI? Diante desse emaranhado de questões, como fazer ressoar o pensamento-diferença para movimentar ainda mais o campo curricular como micromacropolíticas educacionais?

\section{Referências}

CARVALHO, Janete Magalhães. O cotidiano escolar como comunidade de afetos. Petrópolis: DP et Alii, 2009. 
CARVALHO, Janete Magalhães. The Journal Transnational Curriculum Inquiry and the space-time of cosmopolitan hospitality and of curriculum field studies deconstruction.

Transnational Curiculum Inquiry, v. 10, n. 1, p. 1-15, 2013.

DELEUZE, Gilles. Diferença e repetição. Tradução de Luiz Orlandi e Roberto Machado. Rio de Janeiro: Graal, 1988.

DELEUZE, Gilles; PARNET, Claire. Diálogos. Tradução de Eloísa Ribeiro. São Paulo: Escuta, 1998.

DELEUZE, Gilles; GUATTARI, Félix. Mil platôs: capitalismo e esquizofrenia. São Paulo: Editora 34, 1997. v. 1.

DELEUZE, Gilles; GUATTARI, Félix. Mil platôs: capitalismo e esquizofrenia 2. Tradução de Peter PálPelbart e Janice Caiafa. São Paulo: Editora 34, 2012. v. 5.

FOUCAULT, Michel. A arqueologia do saber. Rio de Janeiro: Forense Universitária, 2013.

FOUCAULT, Michel. Microfísica do poder. Rio de Janeiro: Edições Graal, 2007.

GUATTARI, Felix. Caosmose: um novo paradigma estético. Tradução de Ana Lúcia de Oliveira e Lúcia Cláudia Leão. São Paulo: Editora 34, 2012. 